\title{
The Impact of Business Expertise on Information System Data and Analytics Resilience (ISDAR) for Disaster Recovery and Business Continuity: An Exploratory Study
}

\author{
James A. Rodger ${ }^{1}$, Ganesh Bhatt ${ }^{2}$, Pankaj Chaudhary ${ }^{1}$, Germaine Kline ${ }^{1}$, William McCloy ${ }^{3}$ \\ ${ }^{1}$ Indiana University of Pennsylvania, MIS and Decision Sciences, Eberly College of Business \& Information \\ Technology, Indiana, PA, USA \\ ${ }^{2}$ Department of Information Science \& Systems, Morgan State University, Baltimore, MD, USA \\ ${ }^{3}$ Human Resources Management Consultant, Wexford, PA, USA \\ Email: jrodger@iup.edu, pankaj@iup.edu, gpkline@iup.edu, BillMcCloy@comcast.net
}

Received 8 June 2015; accepted 7 July 2015; published 10 July 2015

Copyright () 2015 by authors and Scientific Research Publishing Inc.

This work is licensed under the Creative Commons Attribution International License (CC BY). http://creativecommons.org/licenses/by/4.0/

(c) (i) Open Access

\begin{abstract}
Disaster recovery (DR) and business continuity (BC) have been important areas of inquiry for both business managers and academicians. It is now widely believed that for achieving sustainable business continuity, a firm must be able to recover from both man-made and natural disasters. This is especially true for maintaining and recovering the lifeline of the organization and its data. Although the literature has discussed the importance of disaster recovery and business continuity, there is not much known about how Information System Data Analytics Resilience (ISDAR) and the organization's ability to recover from lost information. In this research, we take a step in this direction and analyze the relationship of IS personnel expertise on ISDAR and investigate Information System (IS) personnel understanding of the firm's competitive priorities, IS Personnel understanding of business policies and objectives, IS personnel's ability to solve business problems, IS personnel initiatives in changing business processes and their determination and attentiveness to focus on achieving confident leadership in data and analytics resilience. We collected data through a survey of IS and business managers from 302 participants. Our results show that there is evidence to support our hypothesis and that there may indeed be a relationship between these variables.
\end{abstract}

\section{Keywords}

Disaster Recovery, Business Continuity, Data Analytics, Resilience

How to cite this paper: Rodger, J.A., Bhatt, G., Chaudhary, P., Kline, G. and McCloy, W. (2015) The Impact of Business Expertise on Information System Data and Analytics Resilience (ISDAR) for Disaster Recovery and Business Continuity: An Exploratory Study. Intelligent Information Management, 7, 223-229. http://dx.doi.org/10.4236/iim.2015.74017 


\section{Introduction}

The rationale for performing the current research based on the following literature review is to provide companies with IS expertise. Top managers should have disaster recovery plans (DRP) for their information systems and critical databases, because the availability of such information can affect their success. This study was conducted to determine the composition of private companies' IS expertise relationship to DR for their IS, and to explore the most effective means of communicating the importance of a DRP throughout the entire organization in order to preserve BC.

Traditionally information systems (IS) planning was conducted on ad-hoc basis, because IS was considered as a support system performing back-end service functions such as disaster recovery. Therefore, the main function of IS management was to choose those systems that could perform back-end functions efficiently. Since the 1980s, however, IS planning started playing an important role in business planning. However, both business planning and IS planning exercises were done in isolation. Even though business managers acknowledged the key role of IS, but they did not take notice of IS competencies.

Since the 1990s, IS planning and business planning exercises have been conducted in conjunction to each other, where IS strategy and business strategy are considered as reinforcing the business advantages. Despite understanding the importance of IS competencies in business performance, there has not been much research that has examined how a firm over time refines its IS competencies such as expertise in order to investigate ISDAR. This paper fills the gap in the literature and examines empirically how a firm refines its IS expertise competencies, in the context of Big Data Analytics Resilence. Below we provide a literature review and define the concept of IS competencies and ISDAR, in the context of disaster recovery.

Shina et al. [1] provide a prototype as an example from the metal cutting industry, to illustrate that Big Data analytics can enable timely and accurate insights using machine learning and predictive analytics to make better decisions about power consumption. They point out that Big Data analytics can enable timely and accurate insights using machine learning and predictive analytics to make better decisions. They developed a proofof-concept, using open platform solutions including MapReduce, Hadoop Distributed File System (HDFS), and a machine-learning tool in order to present an example of Big Data analytics modeling in the metal cutting industry. Hazen et al. [2] point out that today's supply chain professionals are inundated with data, and they propose methods for monitoring and controlling data quality while addressing the importance of highlighting interdisciplinary complementary theory. Edwards et al. [3] demonstrate various applications of MapReduce can be adopted to analyze patterns of load distribution using parallel node calculations, which can later be scaled up to match the requirements for power utility sector. The paper shows the impact of data analytics on Big Data of smart grids.

Sahebjamnia et al. [4] postulate that businesses are increasingly subject to disruptions and that it is almost impossible to predict their nature, time and extent. They feel that organizations need a proactive approach equipped with a decision support framework to protect themselves against the outcomes of disruptive events. Their proposed model formulates a new multi-objective mixed integer linear programming formulation to allocate internal and external resources to both resuming and recovery plans simultaneously.

Sengupta and Annervaz [5] present DDP-DR: a Data Distribution Planner for Disaster Recovery as an optimal way of backing-up critical business data into data centers (DCs) across several Geographic locations. They describe data distribution planning approaches for both single customer and multiple customer scenarios.

Yu et al. [6] believe that recovery costs are as important as losses for decision-making in disaster mitigation because recovery costs reflect the restorative capacity of affected regions. Their study analyses recovery costs and their results show that the total post-disaster recovery costs in Korea are on average one and a half times the actual losses, mainly because of the private sector. They show that the ratios between losses and recovery costs can estimate the recovery costs based on losses given the high correlation.

Lai et al. [7] point out that natural disasters require authorities in charge of recovery, to be accountable to all those involved in the process and that accounting systems can be used to track and account for the fair and transparent management of disaster specific funds, giving visibility to the recovery process and its outcomes. However previous studies suggest that the process of accounting, with its individualizing effects, may create "distance" between the accountor and the accountee, thereby undermining accountability. The authors found that accounting procedures activated after this disaster not only gave visibility to flood damages and recovery actions, but also favored a sense of inter-dependency between all of the players involved and provides evidence of the 
socializing effects of accounting in natural disaster contexts, thereby opening up an interesting area for further research in the streams of critical accounting.

Gaddas et al. [8] contend that as coastal disasters become more frequent and costly, a full assessment of costs becomes more important. In their paper, they identify costs of coastal disasters to human, social, built and natural capital and demonstrate that the spatial and temporal magnitude and scale of costs are captured differently in typical cost accounting and full-cost accounting. They examined how disaster planning and preparedness becomes more cost effective when the full cost of disasters is calculated which sets the stage for rigorous comparisons of strategies for post-disaster development and postulate that full-cost accounting could help reduce vulnerability to future disasters.

Walker 2014 [9] reports that governmental responses to the drought crisis included the establishment of experimental resettlement projects for dislocated families such as the Red River Valley Farms Project in North Dakota, where business and home planning, budgeting and record keeping by client families was compulsory. This study reveals accounting as a key facilitative technology in the recovery phase of a disaster and provided the government with copious data for monitoring the performance of the project, measuring the progress of its participants, and identifying where support was most needed.

Asgary et al. [10] studied the 2010 flood in Pakistan and explores the impacts of this flood on small businesses and factors that influenced their disaster recovery. Findings show that ninety percent of the sample businesses re-opened six months after the flood, but that the majority of them were operating with loss and the results also suggest that provision of minimum government and non-governmental support can enhance the speed, quality and sustainability of the small businesses disaster recovery.

Sargiacomo et al. [11] suggest that the role of accounting and other calculative practices in the context of a natural disaster and subsequent emergency-relief effort relies on document analysis and interviews with key participants. Based on the follow-up to an earthquake that occurred in the Abruzzo region of central Italy in 2009, the study considers these practices through the three lenses of private-interest maximization, inequality, and suffering and shows how accounting actors can help bridge the gap between ethics and critical accounting research.

Sword-Daniels et al. [12] believe that long-term disaster recovery studies are necessary in order to understand the process and the changes that are promoted by disasters over many years and they document the use of an inductive timeline in a retrospective study of disaster recovery for the healthcare system in Montserrat, West Indies.

Silver and Grekkkk-Martin [13] examine the impacts of the F3 tornado that struck the commercial and civic heart of the community of Goderich, Ontario, Canada on 21 August 2011. And demonstrated that participants also relayed positive outcomes stemming from their shared experiences during and after the disaster, including strong feelings of social cohesion and optimism.

Cheng et al. [14] assert that both ICT and mass media have played an influential role after the Great East Japan Earthquake and they explore if they can also contribute to longer term post-disaster recovery. Their study proposes a two-model approach to examine the effects of ICT and mass media in post-disaster recovery from two different perspectives in media studies: the active and passive audience perspectives. They concluded that there was a consistent pattern that the use of both ICT and mass media can create positive effects in post-disaster recovery and argue that both ICT and mass media can have positively contributed to the recovery.

\section{Methodology and Model}

In this paper, we collected data from an online survey and the Compustat database. The survey was targeted to IS managers, working in Fortune 1000 companies. IS Competencies have been extensively used in IS literature and several well defined scale are available for measuring flexible IS infrastructure, shared IS-Business expertise, and trusting IS-Business relationships. Control variables, such as the size, age, and industry type will be measured from the Compustat database. Data was analyzed through hierarchical regression analysis in order to understand the relationship of expertise on Big Data Analytics Resilience. We utilized the following questions in our survey:

E1Question 6: Our IS personnel understand business opportunities.

E2Question 7: Our IS personnel understand the firm's competitive priorities.

E3Question 8: Our IS Personnel understand business policies and objectives. 
E4Question 9: Our IS personnel solve business problems.

E5Question 10: Our IS personnel take initiatives in changing business processes.

D4.Determined and attentive to focus on achieving confident leadership in data and analytics resilience.

\subsection{Shared IS Business Expertise}

Shared IS-Business expertise refers to extent to which IS groups possess an understanding of business objectives and strategies, and management understands the potential of IT. The mutual understanding of IT and business strategies between IS and line management is considered important for firms in creating a shared understanding of goals and long-term objectives of the business (Ross et al., [15]. Kadan et al., [16] examines whether financial analysts exhibit industry expertise. In a similar manner, Bradshaw [17] also investigates a large sample of explicit industry recommendations, and provides insight in to financial research-industry expertise. Lehoux et al., [18] argue that academic spin-offs often lack business expertise, but in spite of this vagueness, academic entrepreneurs must establish trustworthy relation-ships with potential users. Their study highlights the mediating mechanisms by which business models and technology design influence each other. The shared knowledge that IS and business personnel require to plan business and IS strategy does not occur automatically. Neither does it results from college education, nor can it be acquired from imitation. It is rather a continued practice of learning by both IS and line management and understanding each other's perspectives.

\subsection{IS Data Analytics Resilience}

ISDAR is important because current relational and NoSQL database systems are not designed to be resilient. Most current data systems support create, read, update, and delete operations. However, update and delete have immense potential to cause data corruption. Therefore, with current data systems, it is too easy to delete an entire table of data when we intended to simply delete a single row and it is far too easy for a software bug or hardware failure to corrupt data. Dinu and Ng [19] point out that job re-computation should be a first-order failure resilience strategy for big data analytics because multi-job I/O-intensive big-data computations can suffer a significant performance hit, due to relying on data replication as the main failure resilience strategy. Big Data Analytics Resilience projects are important to organizational learning because they need to be open to managers to face, report, and discuss failures. Since Big Data technology is still in a learning phase, failure and the learning and insights resulting from it should be accepted and appreciated within the enterprise. While it is a hackneyed expression that technology is changing the world around us, and that "The Internet of Things" has created new and powerful data streams, it is BDARISC that has the potential to be of tremendous value in many aspects of business and organizational learning. One potential benefit of BDARISC is that it can help to mitigate catastrophic events by enhancing organizational preparedness, reducing the impact of catastrophic enterprise events, increasing the efficiency of industry response, and enabling the more rapid recovery of business and individual livelihoods.

H0: Business Expertise will have a positive relationship with Big Data Analytics Resilience and Recovery.

\section{Results}

The R-square in Table 1 shows a 74.6\% goodness of fit, meaning that approximately here fourth of the variation in the dependent variable of ISDAR is explained by the five expertise variables. Table 2 ANOVA results show a significant relationship with $\mathrm{p} \leq 0.000$. The individual contributions are demonstrated in Table 3 . These results indicate that the IS personnel's ability to solve business problems and to take initiatives in changing business processes such as BC and DR are significant at the $\mathrm{p} \leq 0.000$ level, respectively, for ISDAR. Table 4 Shows significant relationships between the variables with the integrated ISDAR having a significant relationship at the 0.01 level of significance and correlated for e1 (0.497), e2 (0.230), e3 (0.716), e4 (0.627) and e5 (0.818) respectively. Table 5 gives a good internal consistency for the six variables with a Cronbach's Alpha reliability statistic of 0.859 .

\section{Conclusions Recommendations and Future Issues}

The current exploratory study makes several contributions to the literature. First, it is the first generalizable, national survey to attempt to investigate the impact of IS personnel expertise on ISDAR. Second, it reveals that IS personnel expertise improves the ISDAR. Third, regression analysis strengthens the claim that IS Personnel 
Table 1. Model summary.

\begin{tabular}{ccccc}
\hline Model & $\mathrm{R}$ & $\mathrm{R}$ Square & Adjusted R Square & Std. Error of the Estimate \\
1 & $0.864^{\mathrm{a}}$ & 0.746 & 0.742 & 0.34645 \\
\hline
\end{tabular}

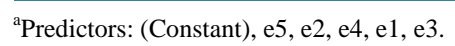

Table 2. ANOVA ${ }^{\mathrm{a}}$.

\begin{tabular}{ccccccc}
\hline & Model & & Sum of Squares & df & Mean Square & F \\
\hline & & Regression & 104.54 & 5 & 20.90 & 174.20 \\
& Residual & 35.527 & 296 & 0.120 \\
& Total & 140.07 & 301 & & \\
& & & & &
\end{tabular}

a Dependent variable: INT, ${ }^{\mathrm{b}}$ Predictors: (Constant), e5, e2, e4, e1, e3.

Table 3. Coefficients ${ }^{\mathrm{a}}$.

\begin{tabular}{|c|c|c|c|c|c|c|}
\hline \multirow{2}{*}{\multicolumn{2}{|c|}{ Model }} & \multicolumn{2}{|c|}{ Unstandardized Coefficients } & \multirow{2}{*}{$\begin{array}{c}\text { Standardized Coefficients } \\
\text { Beta }\end{array}$} & \multirow{2}{*}{$\mathrm{t}$} & \multirow{2}{*}{ Sig. } \\
\hline & & B & Std. Error & & & \\
\hline \multirow{6}{*}{1} & (Con) & 0.783 & 0.170 & & 4.619 & 0.000 \\
\hline & e1 & -0.034 & 0.033 & -0.045 & -1.010 & 0.313 \\
\hline & e2 & 0.002 & 0.030 & 0.003 & 0.075 & 0.940 \\
\hline & e3 & 0.040 & 0.049 & 0.044 & 0.819 & 0.413 \\
\hline & e4 & 0.268 & 0.038 & 0.300 & 7.142 & 0.000 \\
\hline & e5 & 0.564 & 0.040 & 0.671 & 14.094 & 0.000 \\
\hline
\end{tabular}

${ }^{\mathrm{a}}$ Dependent variable: INT.

Table 4. Correlations.

\begin{tabular}{|c|c|c|c|c|c|c|c|}
\hline & & e1 & e2 & e3 & e4 & e5 & INT \\
\hline \multirow{3}{*}{ e1 } & Pear Corr & 1 & $0.542^{* *}$ & $0.595^{* *}$ & $0.409^{* *}$ & $0.585^{* *}$ & $0.497^{* *}$ \\
\hline & Sig. (2-tail) & & 0.000 & 0.000 & 0.000 & 0.000 & 0.000 \\
\hline & $\mathrm{N}$ & 302 & 302 & 302 & 302 & 302 & 302 \\
\hline \multirow{3}{*}{ e2 } & Pear Corr & $0.542^{* *}$ & 1 & $0.306^{* * *}$ & $0.448^{* *}$ & $0.156^{* *}$ & $0.230^{* *}$ \\
\hline & Sig. (2-tail) & 0.000 & & 0.000 & 0.000 & 0.007 & 0.000 \\
\hline & $\mathrm{N}$ & 302 & 302 & 302 & 302 & 302 & 302 \\
\hline \multirow{3}{*}{ e3 } & Pear Corr & $0.595^{* *}$ & $0.306^{* *}$ & 1 & $0.658^{* *}$ & $0.747^{* *}$ & $0.716^{* *}$ \\
\hline & Sig. (2-tail) & 0.000 & 0.000 & & 0.000 & 0.000 & 0.000 \\
\hline & $\mathrm{N}$ & 302 & 302 & 302 & 302 & 302 & 302 \\
\hline \multirow{3}{*}{ e4 } & $\begin{array}{l}\text { Pear } \\
\text { Corr }\end{array}$ & $0.409^{* *}$ & $0.448^{* *}$ & $0.658^{* *}$ & 1 & $0.470^{* * *}$ & $0.627^{* *}$ \\
\hline & Sig. (2-tail) & 0.000 & 0.000 & 0.000 & & 0.000 & 0.000 \\
\hline & $\mathrm{N}$ & 302 & 302 & 302 & 302 & 302 & 302 \\
\hline \multirow{3}{*}{ e5 } & Pear Corr & $0.585^{* *}$ & $0.156^{* *}$ & $0.747^{* *}$ & $0.470^{* *}$ & 1 & $0.818^{* *}$ \\
\hline & Sig. (2-tail) & 0.000 & 0.007 & 0.000 & 0.000 & & 0.000 \\
\hline & $\mathrm{N}$ & 302 & 302 & 302 & 302 & 302 & 302 \\
\hline \multirow{3}{*}{ INT } & Per Corr & $0.497^{* *}$ & $0.230^{* *}$ & $0.716^{* *}$ & $0.627^{* *}$ & $0.818^{* *}$ & 1 \\
\hline & Sig. (2-tail) & 0.000 & 0.000 & 0.000 & 0.000 & 0.000 & \\
\hline & $\mathrm{N}$ & 302 & 302 & 302 & 302 & 302 & 302 \\
\hline
\end{tabular}

${ }^{* *}$ Correlation is significant at the 0.01 level (2-tailed). 
Table 5. Reliability statistics.

\begin{tabular}{cc}
\hline Cronbach's Alpha & N of Items \\
\hline 0.859 & 6 \\
\hline
\end{tabular}

expertise has an impact on ISDAR as evidenced by an R square of $74.6 \%$, overall significant model of $p<0.000$ and individual contributions from several of the independent variables. The model presented here is unique because it incorporates ISDAR into the DR and BC resilience model. We adapted the DR and BC model to develop an instrument for obtaining manager evaluations of expertise and ISDAR. The results showed that the major factors that affected overall integrated ISDAR were that IS personnel had an understanding of the firm's competitive priorities, IS Personnel had an understanding of business policies and objectives, IS personnel's ability to solve business problems, IS personnel initiatives in changing business processes and their determination and attentiveness to focus on achieving confident leadership in data and analytics resilience. Our results indicate that IS personnel initiatives in changing business processes and their determination and attentiveness to focus on achieving confident leadership in data and analytics resilience contribute the most to our model. Study participants were satisfied that these variables measured ISDAR. Overall, participants indicated that the individual constructs had significant potential utility for ISDAR.

This study suggests several potential avenues for future research. First, future research needs to examine populations other than management to determine the consequences of ISDAR. Moreover, individual differences due to gender or personality traits may have different effects on ISDAR. Second, researchers should examine consequences of change in ISDAR to clarify the role of day-to-day operations and disaster recovery. Third, simple ISDAR experiments could be performed to determine whether data and analytics also have a relationship with flexibility, trust relationships and business performance. Fourth, the role of the interactions of IS professionals and administrators in this area should be studied. Fifth, researchers need to determine whether ISDAR leads itself to benefiting from a more robust, larger SEM model that includes these other constructs. Studying interactions between these variables will also be useful and may provide more insight.

This model was designed to answer the following research question:

H0: Business Expertise will have a positive relationship with Big Data Analytics Resilience and Recovery.

All five correlations were significant. Because this correlation of expertise and ISDAR was previously hypothesized, we can establish that the hypothesis is accepted and that the expertise variables of IS personnel understanding of the firm's competitive priorities, IS Personnel understanding of business policies and objectives, IS personnel's ability to solve business problems, IS personnel initiatives in changing business processes and their determination and attentiveness to focus on achieving confident leadership in data and analytics resilience are correlated with ISDAR.

\section{References}

[1] Shina, S.J., Woo, J. and Rachuria, S. (2014) Predictive Analytics Model for Power Consumption in Manufacturing. Procedia CIRP, 15, 153-158. http://dx.doi.org/10.1016/j.procir.2014.06.036

[2] Hazen, B.T., Boone, C.A., Ezell, J.D. and Jones-Farmer, L.A. (2014) Data Quality for Data Science, Predictive Analytics, and Big Data in Supply Chain Management: An Introduction to the Problem and Suggestions for Research and Applications. International Journal of Production Economics, 154, 72-80.

[3] Edwards, M., Rambani, A., Zhu, Y. and Musavi, M. (2012) Design of Hadoop-Based Framework for Analytics of Large Synchrophasor Datasets. Procedia Computer Science, 12, 254-258. http://dx.doi.org/10.1016/j.procs.2012.09.065

[4] Sahebjamnia, N., Torabi, S.A. and Mansouri, S.A. (2015) Integrated Business Continuity and Disaster Recovery Planning: Towards Organizational Resilience. European Journal of Operational Research, 242, 261-273. http://dx.doi.org/10.1016/j.ejor.2014.09.055

[5] Sengupta, S. and Annervaz, K.M. (2014) Multi-Site Data Distribution for Disaster Recovery—A Planning Framework. Future Generation Computer Systems, 41, 53-64. http://dx.doi.org/10.1016/j.future.2014.07.007

[6] Yu, S., Kim, S., Oh, C.W. and Kim, H.A. (2015) Quantitative Assessment of Disaster Resilience: An Empirical Study on the Importance of Post-Disaster Recovery Costs. Reliability Engineering \& System Safety, 137, 6-17. http://dx.doi.org/10.1016/j.ress.2014.12.007

[7] Lai, A., Leoni, G. and Stacchezzini, R. (2014) The Socializing Effects of Accounting in Flood Recovery. Critical 
Perspectives on Accounting, 25, 579-603.

http://dx.doi.org/10.1016/j.cpa.2014.04.002

[8] Gaddis, E.B., Miles, B., Morse, S. and Lewis, D. (2007) Full-Cost Accounting of Coastal Disasters in the United States: Implications for Planning and Preparedness. Ecological Economics, 63, 307-318.

http://dx.doi.org/10.1016/j.ecolecon.2007.01.015

[9] Walker, S.P. (2014) Drought, Resettlement and Accounting. Critical Perspectives on Accounting, 25, 604-619. http://dx.doi.org/10.1016/j.cpa.2013.06.005

[10] Asgary, A., Imtiaz Anjum, M. and Azimi, N. (2012) Disaster Recovery and Business Continuity after the 2010 Flood in Pakistan: Case of Small Businesses. International Journal of Disaster Risk Reduction, 2, 46-56. http://dx.doi.org/10.1016/j.ijdrr.2012.08.001

[11] Sargiacomo, M., Ianni, L. and Everett, J. (2014) Accounting for Suffering: Calculative Practices in the Field of Disaster Relief. Critical Perspectives on Accounting, 25, 652-669. http://dx.doi.org/10.1016/j.cpa.2014.03.011

[12] Sword-Daniels, V.L., Twigg, J. and Loughlin, S.C. (2015) Time for Change? Applying an Inductive Timeline Tool for a Retrospective Study of Disaster Recovery in Montserrat, West Indies Original. International Journal of Disaster Risk Reduction, 12, 125-133. http://dx.doi.org/10.1016/j.ijdrr.2014.12.006

[13] Silver, A. and Grek-Martin, J. (2015) Now We Understand What Community Really Means: Reconceptualizing the Role of Sense of Place in the Disaster Recovery Process. Journal of Environmental Psychology, 42, 32-41. http://dx.doi.org/10.1016/j.jenvp.2015.01.004

[14] Cheng, J.W., Mitomo, H., Otsuka, T. and Jeon, S.Y. (2015) The Effects of ICT and Mass Media in Post-Disaster Recovery-A Two Model Case Study of the Great East Japan Earthquake. Telecommunications Policy, 39, 512-535.

[15] Ross, J.W., Beath, C.M. and Goodhue, D. (1996) Develop Long-Term Competitiveness through IT Assets. Sloan Management Review, 38, 31-45.

[16] Kadan, O., Madureira, L., Wang, R. and Zach, T. (2012) Analysts’ Industry Expertise. Journal of Accounting and Economics, 54, 95-120.

[17] Bradshaw, M.T. (2012) Discussion of “Analysts Industry Expertise”. Journal of Accounting and Economics, 54, 121-131. http://dx.doi.org/10.1016/j.jacceco.2012.09.003

[18] Lehouxa, G., Daudelin, B., Williams-Jones, J.L., Denis, L. and Longo, C. (2014) How Do Business Model and Health Technology Design Influence Each Other? Insights from a Longitudinal Case Study of Three Academic Spin-Offs. Research Policy, 43, 1025-1038. http://dx.doi.org/10.1016/j.respol.2014.02.001

[19] Dinu, F. and Ng, T.S. (2014) Failure Resilience for Big Data Analytics. Rice University, Technical Report TR13-04.

\section{Appendix A}

\section{Participants}

Participants were 302 (50\% male and $49 \%$ female and $1 \%$ no response) public and private employees of age $(18-25=28 \%, 26-64=63 \%$ and $>65=9 \%)$. The participants were located from around the world. The sample was predominantly Caucasian (52\%), with Hispanic (12\%) and Asian (15\% and African American $=17 \%$ and Native American $=4 \%$ ) individuals, in the sample. Participants ranged from an educational level of an Associate's Degree to a Doctorate Degree. That ranged from less than 1 million to greater than 100 billion in annual revenue. In order to qualify for this research, participants had to fit into one of the primary industry classifications of the NAICS Sector. The number of full time employees ranged from less than 1000 to between 51,000 and 550,000. The majority of the participants were top management, with 11\% CEO, 17\% CIO, 11\% CFO, 14\% COO. Participants ranged from less than 10 years' experience (34\%), to 10 - 15 (39\%) to more than 25 years (3\%). 